\title{
EFFECT OF ENZYMATIC CONVERSION OF LACTOSE ON THE FLAVOUR PROFILE OF GOAT MILK KEFIR AND ITS PERMEATE AFTER MICROFILTRATION
}

\author{
Ł.K. KACZYŃSKI* and D. CAIS-SoKolIŃSKA \\ Department of Dairy Products Quality, Faculty of Food Science and Nutrition, Poznań University of Life Sciences, \\ ul. Wojska Polskiego 31, 60-624 Poznań. Poland
}

(Received: 1 December 2017; accepted: 12 March 2018)

The aim of the study was to analyse the flavour profile and general lust of innovative dairy products - kefir, which has increased health-oriented values resulting from an increase in the ratio of whey protein and an enzymatic bioconversion of lactose. Kefir was prepared from a mixture of goat milk and its permeate concentrated with microfiltration and ultrafiltration processes, combined in a ratio of $6: 4$. The permeate addition increases sweetness and reduces overall flavour of the dairy. The enzymatic conversion of lactose into galactooligosaccharides further increases the sweetness of the dairy mixture, while simultaneously weakening the odours both goatish and processed. Keywords: galactooligosaccharides, kefir, goat milk, permeate

The market for goat milk products is a dynamic sector of the dairy industry. Because of the lower content of calcium ions and a lower degree of hydration of casein micelles compared to other types of milk, goat milk is not particularly stable thermally, thus development of technological processes in lower than typical temperature ranges is needed. In addition, membrane-based technologies, e.g. microfiltration, have been proven applicable to processing of goat milk. Today, many dairy plants separate casein and whey proteins in order to increase productivity and improve the quality of the produced cheese (NELSON \& BARBANO, 2005). The resulting permeate contains native whey proteins, which carry many bioactive substances. Thus, proper utilization of this valuable raw material is of great importance as far as the economy is concerned.

The overriding aim of the current study was to analyse the flavour profile and the general desirability of an innovative product, kefir, which has increased health-oriented values resulting from an increase in the ratio of whey protein and an enzymatic bioconversion of lactose into galactooligosaccharides (GOS). Enzymatic conversion of lactose into GOS makes the product sweeter. Lactose has a sweetness of $20 \%$ of sucrose as standard (100\%). Glucose has sweetness on the level $70-80 \%$, galactose $35 \%$. According to FoDA and coworkers (2009), sweetness of GOS is $35 \%$ of the sweetness of sucrose. TORRES and coworkers (2010) stated that GOS sweetness is about 0.3-0.6 times that of sucrose. According to ZADOW (1986), hydrolysis of 70\% of lactose in milk increases sweetness. The sweetness increase is the same as obtained by the addition of $2 \%$ sucrose. Experiments with GOS synthesis in goat milk were conducted by PRUKSASRI \& SupEe (2013). They showed that more points for overall acceptability were given by panellists who drink goat milk in a regular basis to goat milk with higher amounts of GOS (13.2\% GOS content in total sugar) than goat

\footnotetext{
* To whom correspondence should be addressed.

Phone: +48 6184873 17; e-mail: lukasz.kaczynski@up.poznan.pl
}

0139-3006 C 2018 Akadémiai Kiadó, Budapest 
milk with higher amounts of glucose and galactose (8.7\% GOS content in total sugar). In addition, GOS content of milk may lead to a different metabolization of the flavour compounds by the starter cultures during fermentation.

Specifically, kefir was prepared from a mixture of goat milk and its permeate concentrated with microfiltration and ultrafiltration processes $(\mathrm{MF} / \mathrm{UF})$, containing whey protein. The combination of goat milk with MF/UF permeate in a ratio of $60: 40(\%, \mathrm{v} / \mathrm{v})$ allowed for the alteration of the ratio of casein to whey protein from 4.2 in goat milk to 1.1 when milk was mixed with permeate in the above proportion. It was assumed that this is a ratio at which the ratio of lactose (L) to protein (TP) is at an intermediate level between goat milk (1.3) and the permeate (1.6), giving an L:TP ratio of 1.4. Hypothesis: that an innovative product - kefir - is acceptable to consumers, and that an innovative product can be produced from goat milk by a combination of membrane techniques, enzymatic lactose bioconversion, and milk-alcohol fermentation.

\section{Materials and methods}

\subsection{Raw milk sample}

Goat milk (Polish White Improved goats) was centrifuged to separate cream. Skimmed milk was subjected to microfiltration using ceramic ISOFLUX ${ }^{\mathrm{TM}}$ membranes of $1.4 \mu \mathrm{m}$ pore size, made of $\mathrm{ZrO}_{2}-\mathrm{TiO}_{2}$ (Tami Industries, Nyons, France). Membranes with a cut-off were used to reduce the number of microorganisms.

\subsection{Mixture of goat milk and permeate MF/UF}

For the second microfiltration (MF) of milk, membranes of $0.14 \mu \mathrm{m}$ pore size were used to aid protein separation. The membranes were of 23 channels with a channel diameter $\varnothing=3.6$ $\mathrm{mm}$, an outside diameter $\varnothing=25 \mathrm{~mm}$, a length of $1178 \mathrm{~mm}$ (Tami Industries, Nyons, France). The feed stream was fed to the interior of the tube in cross-flow with a rate of $4.0-4.5 \mathrm{~m} \mathrm{~s}^{-1}$. The transmembrane pressure during microfiltration totalled $0.5-0.8$ bars. The obtained permeate was subjected to further compaction during the ultrafiltration process (UF). Here, ceramic membranes of Nominal Molecular Weight Cut-Off of $30 \mathrm{kDa}$ (CeRAM INSIDE ISOFLUX ${ }^{\text {TM }}$ Tami Industries, Nyons, France) were used. The UF was carried out to achieve a 4.5-5.0-fold increase in density, Non-fat dry matter in MF/UF permeate was similar to milk. Goat milk and permeate were combined in a ratio of $60: 40(\%, \mathrm{v} / \mathrm{v})$.

\subsection{Enzymatic conversion of lactose into GOS}

To prompt the reaction, a preparation of $\beta$-galactosidase of Kluyveromyces lactis, named GODO-YNL2 (DuPont ${ }^{\mathrm{TM}}$ Danisco A/S, Brabrand, Denmark), was used. This preparation (5000 ONPGU/g) was added to milk and mixtures thereof in an amount of $0.1 \%(\mathrm{w} / \mathrm{v})$. The hydrolysis and transgalactosylation of the milk lactose was carried out at $37^{\circ} \mathrm{C}$ for $6 \mathrm{~h}$. The samples were then pasteurized at $92{ }^{\circ} \mathrm{C}$ for $15 \mathrm{~min}$.

\subsection{Fermentation - kefir production}

The pasteurized milk, permeate, and their mixture after hydrolysis and transgalactosylation of lactose were fermented in a lacto-alcoholic fermentation process using mesophilic strains of lactic acid bacteria: Lactococcus lactis subsp. lactis, Lactococcus lactis subsp. cremoris, 
Lactococcus lactis subsp. lactis biovar diacetylactis, Leuconostoc mesenteroides subsp. cremoris, Lactobacillus plantarum, Lactobacillus casei, and the yeast Kluyveromyces fragilis (Kluyveromyces marxianus subsp. marxianus). The mixture of starter cultures used was a commercial product, specifically sold under the joint trading code of 75106 from Abiasa Inc.'s (Quebec, Canada) collection. The starter culture was introduced in a lyophilized form at 30 u.a. to 1001 of milk. Fermentation was carried out at $22{ }^{\circ} \mathrm{C}$ for $36 \mathrm{~h}$. The dose of introduced cultures was selected so that the end point of the fermentation would be a product with a $\mathrm{pH}$ value of 4.4 and titratable acidity equal to $31^{\circ} \mathrm{SH}$ (Soxhlet-Henkel degrees). Next, the temperature was lowered to $15^{\circ} \mathrm{C}$, at which the kefir was portioned into individual pieces of packaging with a capacity for $150 \mathrm{~g}$ of product and cooled to a temperature of $5^{\circ} \mathrm{C}$ to complete the fermentation. The resulting products were tested $48 \mathrm{~h}$ after the end of the fermentation process (Fig. 1).

\subsection{Compositional analysis}

Determination of the basic chemical composition of milk and milk mixture with its MF/UF permeate was conducted using standard methods (AOAC, 1995; CHEVER et al., 2014). The $\mathrm{pH}$ was measured using a CP-411 pH-meter (Elmetron, Zabrze, Poland). The GOS composition was determined using LC-MS instead of HPAE-PAD to detect galactose, glucose, and lactose (Slegte, 2002). An ion-exclusion high-performance liquid chromatography electrospray ionization mass spectrometry (IEHPLC-ESI-MS) analysis was performed using a Dionex UltiMate 3000 UHPLC (Thermo Fisher Scientific, Sunnyvale, CA, USA) coupled to a Bruker maXis impact ultra-high resolution orthogonal quadrupoletime-of-flight accelerator (qTOF) equipped with an ESI source and operated in positive ion mode (Bruker Daltonik, Bremen, Germany). The IE chromatographic separation was achieved with a Rezex ${ }^{\mathrm{TM}} \mathrm{RCM}-$ Monosaccharide $\mathrm{Ca}^{2+}(8 \%), 300 \times 7.8 \mathrm{~mm}$ LC column (Phenomenex, Torrance, CA, USA) instrument.

\subsection{Sensory analysis}

The sensory analysis was carried out using quantitative descriptive analysis (QDA). Samples of milk, its mixture $(50 \mathrm{ml})$, and kefir $(30 \mathrm{~g})$, were served at $7{ }^{\circ} \mathrm{C}$ in glasses coded with 3-digit random numbers. QDA was performed in triplicate using 9 trained panellists (4 women, 5 men; age range 21-57 years). Intensity of odour and taste was assessed based on a nonstructured 9 step intensity scale ranging from a score of 1 (extremely weak) to a score of 10 (extremely strong). At the outset, the evaluation panel developed its own vocabulary of sensory characteristics in accordance with guidelines described by WRÓBLEWSKA and coworkers (2009) and ADHIKARI and co-workers (2010). Finally, 10 attributes were selected related to odour and taste of goat milk and its mixture, and 18 attributes related to odour, taste, and mouthfeel of kefirs, which were exactly defined for profiling.

\subsection{Acceptance test}

In the evaluation of overall desirability of kefir, a hedonic scale was used with intensity ranging from 1 to 9 points, where 1 denotes an exceptionally desirable sample and 9 is exceptionally undesirable (ISO, 2003). Evaluated quality attributes included taste, aroma, appearance, colour, and consistency. The participants (127 persons, aged 19-56 years) assessing the samples were frequent goat milk consumers. 


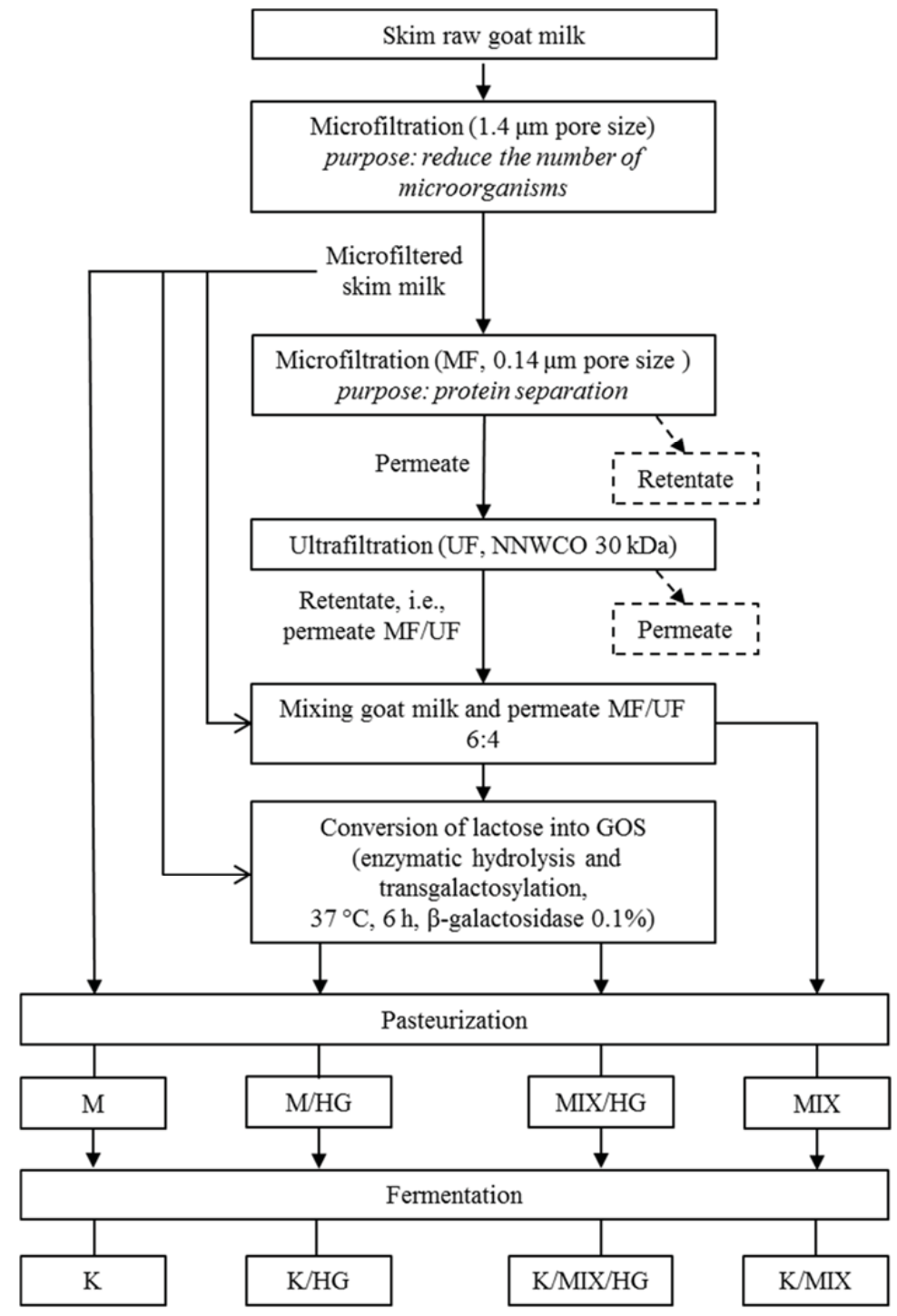

Fig. 1. Flow sheet of kefir production

M: pasteurized goat milk; M/HG: pasteurized goat milk after enzymatic conversion of lactose; MIX: pasteurized mixture of milk and its permeate; MIX/HG: pasteurized mixture of milk and its permeate after enzymatic conversion of lactose; K: kefir from pasteurized goat milk; K/HG: kefir from pasteurized goat milk after enzymatic conversion of lactose; K/MIX: kefir from pasteurized mixture of milk and its permeate; K/MIX/HG: kefir from pasteurized mixture of milk and its permeate after enzymatic conversion of lactose

\subsection{Statistical evaluation}

The statistical calculations were performed using Statistica data analysis software version 10 (StatSoft Inc). To verify the statistical hypotheses, a univariate ANOVA analysis was employed. 


\section{Results and discussion}

In the MF/UF permeate, total protein content was $27.8 \mathrm{~g} \mathrm{~kg}^{-1}$ (these were only whey proteins) and the amount of lactose was $43.4 \mathrm{~g} \mathrm{~kg}^{-1}$. The average solid non-fat content of permeate and milk was high, $85.1 \mathrm{~g} \mathrm{~kg}^{-1}(\mathrm{P}>0.05)$. The combination of goat milk with its permeate increased whey protein content more than twofold (Table 1). Furthermore, in mixtures (MIX, MIX/ $\mathrm{HG})$, there was $5.5 \%$ less total protein than in milk (M, M/HG). The processes of enzymatic conversion of lactose into GOS reduced the content of lactose in milk by $99.5 \%$ and in the mixture by $99.8 \%$.

Table 1. Physicochemical characteristics (gross composition) of goat milk and its mixture with its permeate (6:4) before and after enzymatic bioconversion of lactose, $n=9, \pm S D$

\begin{tabular}{lcccc}
\hline Parameters & $\mathrm{M}$ & $\mathrm{M} / \mathrm{HG}$ & $\mathrm{MIX}$ & MIX/HG \\
\hline Solid non-fat $\left(\mathrm{g} \mathrm{kg}^{-1}\right)$ & $85.2 \pm 0.1^{\mathrm{a}}$ & $85.3 \pm 0.3^{\mathrm{a}}$ & $85.1 \pm 0.9^{\mathrm{a}}$ & $85.0 \pm 0.1^{\mathrm{a}}$ \\
Fat $\left(\mathrm{g} \mathrm{kg}^{-1}\right)$ & $0.4 \pm 0.2^{\mathrm{a}}$ & $0.3 \pm 0.4^{\mathrm{a}}$ & $0.3 \pm 0.2^{\mathrm{a}}$ & $0.3 \pm 0.4^{\mathrm{a}}$ \\
Total protein $\left(\mathrm{g} \mathrm{kg}^{-1}\right)$ & $32.0 \pm 0.4^{\mathrm{a}}$ & $32.1 \pm 0.1^{\mathrm{a}}$ & $30.2 \pm 0.5^{\mathrm{a}}$ & $30.4 \pm 0.5^{\mathrm{a}}$ \\
Casein $\left(\mathrm{g} \mathrm{kg}^{-1}\right)$ & $25.8 \pm 0.3^{\mathrm{b}}$ & $25.6 \pm 0.1^{\mathrm{b}}$ & $15.5 \pm 0.7^{\mathrm{a}}$ & $15.1 \pm 0.3^{\mathrm{a}}$ \\
Whey protein $\left(\mathrm{g} \mathrm{kg}^{-1}\right)$ & $6.2 \pm 0.1^{\mathrm{a}}$ & $6.1 \pm 0.5^{\mathrm{a}}$ & $14.4 \pm 0.3^{\mathrm{b}}$ & $13.9 \pm 0.6^{\mathrm{b}}$ \\
Lactose $\left(\mathrm{g} \mathrm{kg}^{-1}\right)$ & $41.4 \pm 0.1^{\mathrm{b}}$ & $0.2 \pm 0.1^{\mathrm{a}}$ & $42.2 \pm 0.1^{\mathrm{b}}$ & $0.1 \pm 0.1^{\mathrm{a}}$ \\
Lactose $(\%$ in total sugars) & 100 & $5.1^{\mathrm{a}}$ & 100 & 5.2 \\
GOS $\%$ in total sugars) & 0 & 0.9 & 0 & 1.2 \\
Glucose (\% in total sugars) & 0 & 48.7 & 0 & 48.0 \\
Galactose (\% in total sugars) & 0 & 45.3 & 0 & 45.6 \\
\hline
\end{tabular}

GOS: galactooligosaccharides; M: pasteurized goat milk; M/HG: pasteurized goat milk after enzymatic conversion of lactose; MIX: pasteurized mixture of milk and its permeate; MIX/HG: pasteurized mixture of milk and its permeate after enzymatic conversion of lactose; SD: standard deviation; a-b: different letters in row indicate statistically significant differences at the level $\alpha=0.05$

The animal and goatish scents were most noticeable in non-hydrolysed goat milk (8.7 and 9.0 score, respectively) and its permeate mixture before hydrolysis ( 8.5 and 8.2 score $)$ (Fig. 2). The least goatish scent was observed in the mixture after enzymatic conversion of lactose into GOS (5.9). The processes of enzymatic conversion of lactose did not significantly change the perceptions of cooked, dairy fat, grains, lack of freshness, light-oxidized, and processed. The same trend has been demonstrated by evaluating the mixture, the only exception being the processed scent. It was determined that the conversion of lactose significantly reduced the odour intensity in the MIX/HG sample (from 3.4 to 2.1 score). On the other hand, sweet smell of dairy increased by a score of $0.8 \mathrm{in} \mathrm{M/HG}$ and 1.0 in $\mathrm{MIX} / \mathrm{HG}$.

No differences in the $\mathrm{pH}$ values of kefir samples were detected measuring a mean $\mathrm{pH}$ of $4.42(\mathrm{P}>0.05)$. In addition, the titratable acidity of kefir from goat milk after enzymatic conversion of lactose into GOS was significantly higher $(3.7 \%)$ than in the other samples.

The majority of samples had a kefir-like odour and taste. A smaller, but statistically significant number of samples were evaluated as possessing a sour odour, sour taste, and aftertaste (Table 2). 


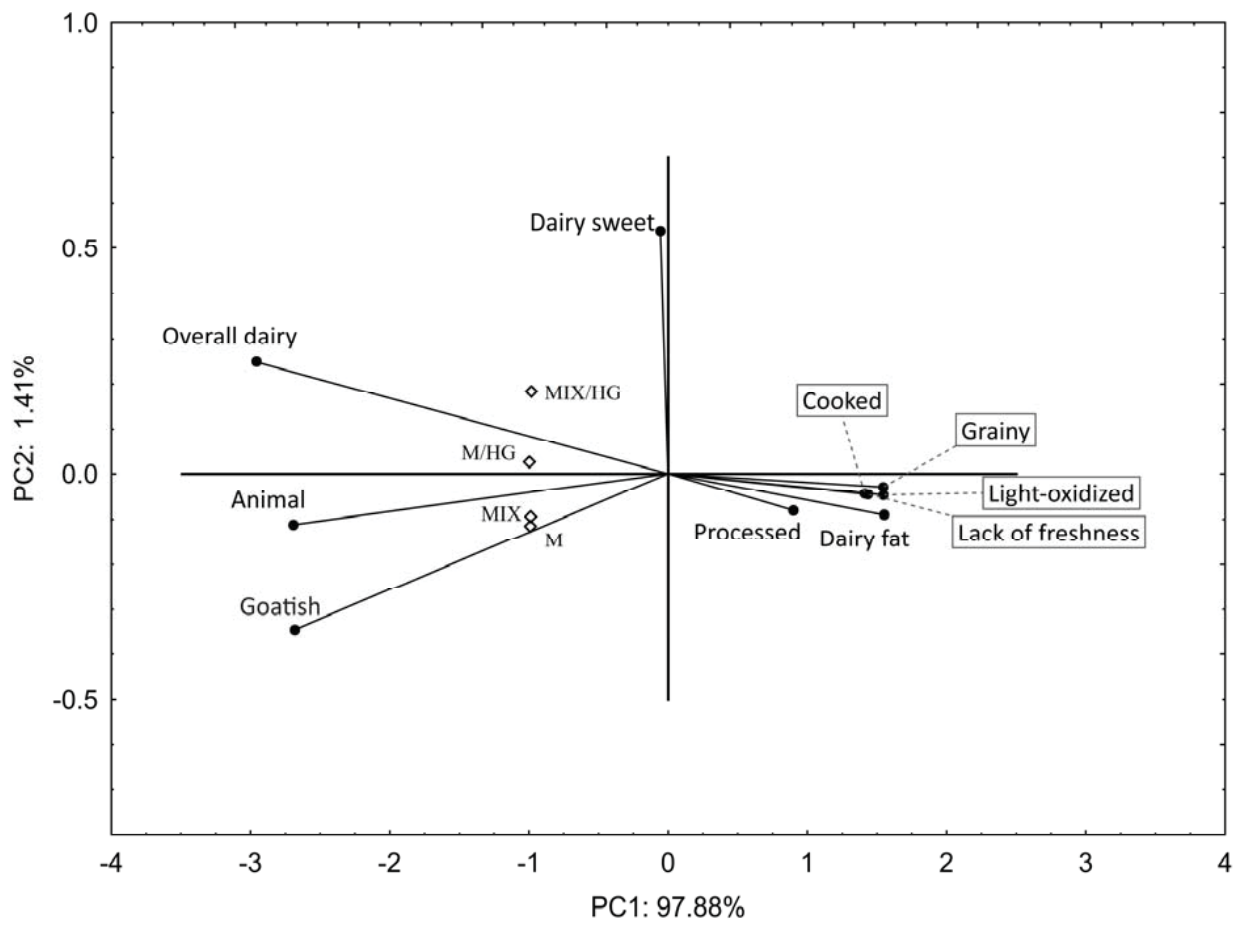

Fig. 2. The Principle Component Analysis for the aroma profiling results of goat milk and its mixture with its permeate after enzymatic conversion of lactose

M: pasteurized goat milk; M/HG: pasteurized goat milk after enzymatic conversion of lactose; MIX: pasteurized mixture of milk and its permeate; MIX/HG: pasteurized mixture of milk and its permeate after enzymatic conversion of lactose; PC: principal component

Table 2. Effect of milk and its mixture type on the descriptive attributes of kefir, $\mathrm{n}=9, \pm \mathrm{SD}$

\begin{tabular}{lcccc}
\hline Descriptors & \multicolumn{1}{c}{ K } & K/HG & K/MIX & K/MIX/HG \\
\hline Attributes of odour & & & & \\
Kefir-like & $8.1 \pm 0.3^{\mathrm{b}}$ & $8.3 \pm 0.1^{\mathrm{b}}$ & $6.6 \pm 0.3^{\mathrm{a}}$ & $6.7 \pm 0.2^{\mathrm{a}}$ \\
Sour & $4.8 \pm 0.3^{\mathrm{a}}$ & $3.7 \pm 0.3^{\mathrm{a}}$ & $3.5 \pm 0.4^{\mathrm{a}}$ & $4.0 \pm 0.1^{\mathrm{a}}$ \\
Sweet & $1.0 \pm 0.1^{\mathrm{a}}$ & $3.2 \pm 0.3^{\mathrm{c}}$ & $1.2 \pm 0.5^{\mathrm{a}}$ & $2.1 \pm 0.3^{\mathrm{b}}$ \\
Creamy & $1.0 \pm 0.3^{\mathrm{a}}$ & $1.1 \pm 0.6^{\mathrm{a}}$ & $1.1 \pm 0.3^{\mathrm{a}}$ & $1.0 \pm 0.3^{\mathrm{a}}$ \\
Medical & $1.0 \pm 0.6^{\mathrm{a}}$ & $1.2 \pm 0.2^{\mathrm{a}}$ & $1.2 \pm 0.4^{\mathrm{a}}$ & $1.2 \pm 0.1^{\mathrm{a}}$ \\
Attributes of taste & & & & \\
Kefir-like & $8.5 \pm 0.3^{\mathrm{c}}$ & $6.8 \pm 0.3^{\mathrm{a}}$ & $7.5 \pm 0.3^{\mathrm{b}}$ & $8.1 \pm 0.3^{\mathrm{c}}$ \\
Sour & $3.7 \pm 0.2^{\mathrm{a}}$ & $4.1 \pm 0.9^{\mathrm{a}}$ & $4.0 \pm 0.4^{\mathrm{a}}$ & $3.5 \pm 0.5^{\mathrm{a}}$ \\
Sweet & $1.5 \pm 0.3^{\mathrm{a}}$ & $2.8 \pm 0.2^{\mathrm{b}}$ & $1.3 \pm 0.5^{\mathrm{a}}$ & $3.4 \pm 0.5^{\mathrm{c}}$ \\
Buttermilk & $2.0 \pm 0.3^{\mathrm{a}}$ & $1.8 \pm 0.1^{\mathrm{a}}$ & $2.1 \pm 0.7^{\mathrm{a}}$ & $4.5 \pm 0.4^{\mathrm{b}}$ \\
Bitter & $1.0 \pm 0.6^{\mathrm{a}}$ & $1.0 \pm 0.1^{\mathrm{a}}$ & $1.0 \pm 0.2^{\mathrm{a}}$ & $1.0 \pm 0.3^{\mathrm{a}}$ \\
\hline
\end{tabular}




\begin{tabular}{lcccc}
\multicolumn{5}{c}{ Table 2. continued } \\
\hline Descriptors & $\mathrm{K}$ & $\mathrm{K} / \mathrm{HG}$ & $\mathrm{K} / \mathrm{MIX}$ & $\mathrm{K} / \mathrm{MIX} / \mathrm{HG}$ \\
\hline Medical & $1.0 \pm 0.1^{\mathrm{a}}$ & $1.2 \pm 0.7^{\mathrm{a}}$ & $1.0 \pm 0.7^{\mathrm{a}}$ & $1.0 \pm 0.4^{\mathrm{a}}$ \\
Aftertaste & $4.5 \pm 0.3^{\mathrm{b}}$ & $5.0 \pm 0.6^{\mathrm{b}}$ & $3.1 \pm 0.3^{\mathrm{a}}$ & $4.7 \pm 0.8^{\mathrm{b}}$ \\
Mouthfeel attributes & & & $5.6 \pm 0.2^{\mathrm{c}}$ \\
Prickling & $2.3 \pm 0.3^{\mathrm{a}}$ & $6.1 \pm 0.2^{\mathrm{c}}$ & $3.7 \pm 0.3^{\mathrm{b}}$ & $1.5 \pm 0.5^{\mathrm{a}}$ \\
Dense & $1.9 \pm 0.2^{\mathrm{a}}$ & $2.0 \pm 0.4^{\mathrm{a}}$ & $1.7 \pm 0.2^{\mathrm{a}}$ & $3.2 \pm 0.4^{\mathrm{a}}$ \\
Creamy & $5.3 \pm 0.2^{\mathrm{b}}$ & $4.7 \pm 0.1^{\mathrm{b}}$ & $3.5 \pm 0.2^{\mathrm{a}}$ & $2.4 \pm 0.7^{\mathrm{b}}$ \\
Smooth & $1.1 \pm 0.1^{\mathrm{a}}$ & $1.2 \pm 0.2^{\mathrm{a}}$ & $2.5 \pm 0.5^{\mathrm{b}}$ & $1.0 \pm 0.6^{\mathrm{a}}$ \\
Mouth-coating & $2.3 \pm 0.5^{\mathrm{b}}$ & $2.2 \pm 0.2^{\mathrm{b}}$ & $1.1 \pm 0.2^{\mathrm{a}}$ & $1.1 \pm 0.1^{\mathrm{a}}$ \\
Fatty & $1.0 \pm 0.4^{\mathrm{a}}$ & $1.1 \pm 0.4^{\mathrm{a}}$ & $1.0 \pm 0.7^{\mathrm{a}}$ & \\
\hline
\end{tabular}

$\mathrm{K}$ : kefir from pasteurized goat milk; K/HG: kefir from pasteurized goat milk after enzymatic conversion of lactose; K/MIX: kefir from pasteurized mixture of milk and its permeate; $\mathrm{K} / \mathrm{MIX} / \mathrm{HG}$ : kefir from pasteurized mixture of milk and its permeate after enzymatic conversion of lactose; SD: standard deviation; a-c: different letters with in row indicate statistically significant differences at the level $\alpha=0.05$

Relatedly, it is interesting to find the taste of buttermilk in permeate kefir after the enzymatic conversion of lactose. The addition of permeate resulted in the creamy attribute being less noticeable in kefir, and the mouth-coating attribute was completely ablated. It has been shown that the enzymatic conversion of lactose into GOS affects only one of the evaluated mouthfeel attributes (prickling). Consumers ranked kefir from mixtures after enzymatic conversion of lactose into GOS the highest (2.6 score), while the goat milk kefir (6.7 score) was evaluated the worst.

MARTINEZ-FEREZ and co-workers (2009) investigated the production of goat milk permeates with a reduced content of protein while recovering the whole oligosaccharide fraction, and showed that goat milk demonstrates interesting similarities compared to human milk with respect to the composition of oligosaccharides. GOS belong to so-called prebiotics, which are non-digestible and show beneficial functions in the human body (Córdova et al., 2017).

PRUKSASRI and SUPEE (2013) described the process of making goat milk containing GOS. The scores of goat milk containing higher amounts of GOS scored very high in taste and overall acceptability when compared to regular goat milk. Furthermore, goat milk containing GOS maintained good stability under acidic conditions. Products made from lactose-free milk are important in the diets of people with lactose intolerance (HARJu et al., 2012), and especially important in the diets of children and adolescents among them. This type of milk in the diet may be the sole source of calcium. Delactosed permeates examined by SMIтH and co-workers (2016) contained $\mathrm{Ca}$ of $0.84 \%$, the characteristics of delactosed permeates were evaluated by descriptive sensory analysis. They showed that salty taste was higher than in standard permeate, as minerals and organic acids concentrated during the lactose removal process. FRANKOWSKI and co-workers (2014) also reported flavours in permeates consistent with other whey and milk products, such as cooked or milky, beefy or brothy, diacetyl, cardboard, and graham cracker. 


\section{Conclusions}

Studies have shown that it is possible to produce kefir from a mixture of goat milk and its permeate concentrated by microfiltration and ultrafiltration processes, then subjected to enzymatic conversion of lactose into GOS. It is an innovative product with pro-health features resulting from increased whey protein content, reduced lactose content, and the presence of GOS.

This innovative kefir has different sensory characteristics than kefir from goat milk. The addition of permeate increases flavour of dairy sweet and reduces overall dairy. The enzymatic conversion of lactose also increases the dairy sweet characteristic. At the same time, these processes contribute to weakening the odours of animal, goatish, and processed. The flavour profile of the mixture after the enzymatic conversion of lactose into GOS has been determined by the general desirability of the kefir produced therefrom, and was more sensory than goat milk kefir. The advantage of kefir from milk and its MF/UF permeate mixtures subjected to enzymatic conversion of lactose into GOS is the intensification of the buttermilk taste and mouthfeel attributes, which include prickling.

\section{References}

Adhikari, K., Dooley, L.M., Chambers, E. \& Bhumiratana, N. (2010): Sensory characteristics of commercial lactose-free milks manufactured in the United States. LWT - Food Sci. Technol., 43, 113-118.

AOAC (1995): Official methods of analysis of the Association of Official Analytical Chemists $16^{\text {th }}$ edition. Association of official analytical chemists AOAC, Arlington, VA. Method no. AOAC 905.02, 990.20, 991.20.

Chever, S., Guyomarc'H, F., Beaucher, E. \& Famelart, M.H. (2014): High-protein fat-free acid milk gels: Control of protein composition and heat treatment. Int. Dairy J., 37, 95-103.

Córdova, A., Astudillo, C., Santibañez, L., Cassano, A., Ruby-Figueroa, R. \& Illanes, A. (2017): Purification of galacto-oligosaccharides (GOS) by three-stage serial nanofiltration units under critical transmembrane pressure conditions. Chem. Eng. Res. Des., 117, 488-499.

FodA, M.I., Kholif, S.M. \& KHolif, A.M. (2009): Evaluation of goat milk containing galactooligosaccharides after supplementing the ration with amino acids. Int. J. Dairy Sci., 4, 27-33.

Frankowski, K.M., Miracle, R.E. \& Drake, M.A. (2014): The role of sodium in the salty taste of permeate. J. Dairy Sci., 97, 5356-5370.

Harju, M., Kallioinen, H. \& Tossavainen, O. (2012): Lactose hydrolysis and other conversions in dairy products: Technological aspects. Int. Dairy J., 22, 104-109.

ISO (2003): Sensory analysis, guidelines for the use of quantitative response scales. International Organization for Standardization (ISO), Geneva, standard no. ISO 4121.

Martinez-Ferez, A., Zapata, J.E., Guadix, A., Almeciua, M.C., Gomez, M. \& Guadix, E.M. (2009): Obtention of goat milk permeates enriched in lactose-derived oligosaccharides. Desalination, 245, 730-736.

Nelson, B.K. \& Barbano, D.M. (2005): A microfiltration process to maximize removal of serum proteins from skim milk before cheese making. J. Dairy Sci., 88, 1891-1900.

Pruksasri, S. \& Supee, K. (2013): Sensory evaluations and stability determinations of goat milk containing galactooligosaccharides. Int. J. Food Sci. Tech., 48, 2456-2462.

SLEGTE, J.D. (2002): Determination of trans-galactooligosaccharides in selected food products by ion-exchange chromatography: Collaborative study. J. AOAC Int., 85, 417-423.

Smith, S.T., Metzger, L. \& Drake, M.A. (2016): Evaluation of whey, milk, and delactosed permeates as salt substitutes. J. Dairy Sci., 99, 8687-8698.

Torres, D.P.M., Goncalves, M.P., Teixeira, J.A. \& Rodrigues, L.R. (2010): Galacto-oligosaccharides: production, properties, applications, and significance as prebiotics. Compr. Rev. Food Sci. F., 9, 438-454

Wróblewska, B., KoŁakowski, P., Pawlikowska, K., Troszyńska, A. \& Kaliszewska, A. (2009): Influence of the addition of transglutaminase on the immunoreactivity of milk proteins and sensory quality of kefir. Food Hydrocolloids, 23, 2434-2445.

ZADow, J.G. (1986): Lactose hydrolysed dairy products. Food Technol. Austr., 38, 460-471. 